\title{
Lítio e neuroproteção: novos usos potenciais em psiquiatria
}

\section{Lithium and neuroprotection: new potential uses in psychiatry}

\author{
Paula V. Nunes ${ }^{1}$, Orestes V. Forlenza ${ }^{2}$, Wagner F. Gattaz ${ }^{3}$ \\ 'Médica psiquiatra, doutora em Psiquiatria pelo Instituto de Psiquiatria do Hospital das Clínicas da Faculdade de Medicina da Universidade de São Paulo (IPq-HC-FMUSP). \\ ${ }^{2}$ Coordenador do Ambulatório de Psicogeriatria (LIM-27) do IPq-HC-FMUSP. \\ ${ }^{3}$ Professor titular e diretor do Laboratório de Neurociências do IPq-HC-FMUSP. \\ Recebido: 15/06/2007 - Aceito: 20/08/2007 \\ Nunes, P.V. et al. / Rev. Psiq. Clin 34 (6); 294-295, 2007
}

Pacientes com doenças psiquiátricas apresentam um risco aumentado para declínio cognitivo e demência. Esse risco parece estar relacionado tanto ao tipo de transtorno mental como também ao seu curso clínico e não aos potenciais efeitos colaterais cognitivos das medicações utilizadas para o tratamento. A grande maioria dos estudos enfatiza a remissão dos sintomas agudos e a prevenção de recaídas dos quadros psiquiátricos, em detrimento da avaliação das manifestações cognitivas no longo termo. O risco para declínio cognitivo parece ser diferente conforme a doença e pacientes com transtorno bipolar apresentam o mais elevado risco de demência, seguidos por pacientes com depressão unipolar, esquizofrenia e neuroses, em uma amostra com 50 anos de idade em média (Kessing et al., 1999).

Em pacientes bipolares, os déficits cognitivos estão associados a uma maior duração da doença e ao maior número de episódios afetivos ao longo da vida (Harvey et al., 1997). Ainda existe debate se a depressão é um fator de risco independente para a demência ou um sinal prodrômico dessa doença. $\mathrm{O}$ tratamento da depressão está associado a uma melhora funcional e também cognitiva. Porém, mesmo os indivíduos que apresentam remissão dos sintomas cognitivos após o tratamento bem-sucedido da depressão apresentam risco aumentado para demência. Em uma meta-análise baseada em estudos prospectivos e de caso-controle, a ocorrência de depressão mostrou-se associada a um risco aumentado para o desenvolvimento de doença de Alzheimer (razão de chance, $O R=1,82$ ). Essa associação parece não ser dependente do tempo entre o início do quadro depressivo e o diagnóstico da demência, pois a razão de risco para os casos de depressão com início até dez anos antes do declínio cognitivo foi semelhante à dos casos com mais de dez anos de história de depressão
(OR=1,60 e 1,92, respectivamente) (revisão em Jorm, 2000). Portanto, uma história prévia de depressão está relacionada a um aumento do risco para o desenvolvimento da doença de Alzheimer ao longo da vida. Essa relação sugere que a depressão pode ser considerada tanto como um fator de risco independente para a doença de Alzheimer, como também como uma manifestação prodrômica da demência, sobretudo nos casos de início tardio, conforme relatado em uma recente meta-análise (Ownby et al., 2006).

Tanto a depressão quanto a doença de Alzheimer estão associadas a uma variedade de alterações neuropatológicas, tais como a perda seletiva de neurônios noradrenérgicos no locus ceruleus e de neurônios serotonérgicos do núcleo dorsal da rafe. Ambas as doenças estão associadas à diminuição de atividade cerebral ou alterações estruturais no córtex orbitofrontal e nos gânglios da base. Anormalidades também podem ser observadas nos lobos temporais basais, giro do cíngulo e tálamo. Dessa forma, os fatores de risco comuns à depressão e à demência estão relacionados à doença cerebrovascular e à perda seletiva de neurônios, muito embora não tenha sido elucidado o mecanismo por meio do qual se dá essa perda no caso da depressão.

Dadas as evidências da associação da depressão com declínio cognitivo, uma das perguntas ainda não respondidas seria se o tratamento da depressão em si poderia ser um fator modificador dessa progressão. Embora comumente se assuma que medicamentos com propriedades anticolinérgicas sejam menos adequados para o tratamento de idosos, não há evidências de que o uso desses fármacos possa causar demência - diferentemente de transtornos cognitivos transitórios. Mesmo no caso dos antidepressivos tricíclicos, a resposta clínica em idosos é completa, com benefícios que incluem também a disfunção cognitiva da depressão. 
Nesse contexto insere-se o papel do lítio no tratamento dos transtornos mentais em idosos. Embora os seus efeitos adversos em curto e longo termo sejam conhecidos, a sua eficácia no manejo dos transtornos do humor é reconhecida há mais de quatro décadas. Mais recentemente, evidências de um possível efeito neurotrófico e neuroprotetor do lítio têm sido acumuladas a partir de estudos laboratoriais e modelos animais, e também de estudos de neuroimagem em humanos.

No âmbito clínico, as primeiras evidências que corroboram esse efeito neuroprotetor do lítio foram produzidas por pesquisadores do Laboratório de Neurociências (LIM-27), no Instituto de Psiquiatria da FMUSP. Em uma amostra de 118 bipolares idosos observou-se uma elevada prevalência de demência $(21,4 \%)$, três vezes maior do que a esperada na população geral. Contudo, essa ocorrência parece ser dependente do tipo de tratamento a que os pacientes foram submetidos ao longo da vida: a prevalência de doença de Alzheimer foi significantemente menor entre os pacientes tratados cronicamente com lítio (4,5\%) em comparação com aqueles tratados com outros estabilizadores do humor (33\%, $\mathrm{p}<0,001)$. Os primeiros também apresentaram uma menor prevalência de comprometimento cognitivo leve, condição associada a um risco aumentado para desenvolver doença de Alzheimer (Nunes et al., 2007).

O lítio é um potente inibidor da enzima glicogênio sintase quinase-3 $\beta$ (GSK-3). A GSK-3 regula uma série de processos neuronais, incluindo a apoptose e a remodelagem do citoesqueleto. $\mathrm{O}$ lítio, por intermédio da inibição da GSK-3, pode exercer ação duplamente favorável sobre as duas principais vias patogênicas da doença de Alzheimer: a cascata do $\beta$-amilóide e a formação dos emaranhados neurofibrilares. O lítio aumenta substancialmente a expressão da Bcl-2, uma importante proteína citoprotetora no sistema nervoso central, tanto em córtex de rato quanto em células humanas de origem neuronal. Além de ações neuroprotetoras, a Bcl-2 parece auxiliar na regeneração de axônios no SNC de mamíferos (revisão em Manji et al., 2000). Em modelos animais, o uso crônico do lítio reduziu dano isquêmico (Nonaka e Chuang, 1998).

Até pouco tempo atrás, a perda ou atrofia de um grande número de neurônios era tida como inerente ao envelhecimento, e a neurogênese no cérebro humano adulto, como um evento improvável. No entanto, juntamente com a identificação de uma série de vias que regulam a sobrevida celular, foi demonstrado que a neurogênese pode ocorrer no cérebro humano adulto. Em ratos, o lítio (em doses terapêuticas) leva a um aumento de neurogênese no giro denteado do hipocampo (Chen et al., 2000). Outras evidências das ações neurotróficas do lítio no cérebro humano vêm de estudos de neuroimagem tanto de espectroscopia demonstrando aumento da viabilidade e função neuronal como de volume cerebral (Yucel et al., 2007).

Assim, parece razoável supor que esse efeito protetor do lítio em relação à doença de Alzheimer, observado em indivíduos idosos portadores do transtorno bipolar, seja uma decorrência de suas propriedades biológicas intrínsecas. Por meio dessa via, o lítio pode inibir processos cruciais para doença de Alzheimer como a superprodução de $\beta$-amilóide e hiperfosforilação da tau, levando à formação dos emaranhados neurofibrilares, talvez prevenindo apoptose e estimulando a neurogênese no hipocampo. A confirmação dessa hipótese necessita de estudos prospectivos, em que sejam feitos controles por parâmetros biológicos e funcionais dos efeitos em longo prazo do lítio sobre a incidência de demência.

\section{Referências}

Chen G.; Rajkowska G.; Du F.; Seraji-Bozorgzad N.; Manji H.K. - Enhancement of hippocampal neurogenesis by lithium. J Neurochem 75: 1729-1734, 2000.

Harvey P.D; Powchik P.; Parrella M.; White L.; Davidson M. - Symptom severity and cognitive impairment in chronically hospitalised geriatric patients with affective disorders. Br J Psychiatry 170: 369-374, 1997.

Jorm A.F. - Is depression a risk factor for dementia or cognitive decline? Gerontology 46: 219-227, 2000.

Kessing L.V; Olsen E.W.; Mortensen P.B.; Andersen P.K. - Dementia in affective disorder: a case-register study. Acta Psychiatr Scand 100: 176-185, 1999.

Manji H.K.; Moore G.J.; Chen G. - Lithium up-regulates the cytoprotective protein $\mathrm{Bcl}-2$ in the CNS in vivo: a role for neurotrophic and neuroprotective effects in manic depressive illness. J Clin Psychiatry 61(Suppl. 9): $82-96,2000$

Nonaka S.; Chuang D.M. - Neuroprotective effects of chronic lithium on focal cerebral ischemia in rats. Neuroreport 9: 2081-2084, 1998.

Nunes P.V.; Forlenza O.V.; Gattaz W.F. - Lithium and risk for Alzheimer's disease in elderly patients with bipolar disorder. Br J Psychiatry 190: 359-360, 2007.

Ownby R.L.; Crocco E.; Acevedo A.; John V.; Loewenstein D. - Depression and risk for Alzheimer disease: systematic review, meta-analysis, and metaregression analysis. Arch Gen Psychiatry 63: 530-538, 2006.

Yucel K.; Taylor V.H.; McKinnon M.C.; Macdonald K.; Alda M.; Young L.T.; Macqueen G.M. - Bilateral hippocampal volume increase in patients with bipolar disorder and short-term lithium treatment. Neuropsychopharmacology. 2007 Apr 4 [Epub ahead of print]. 